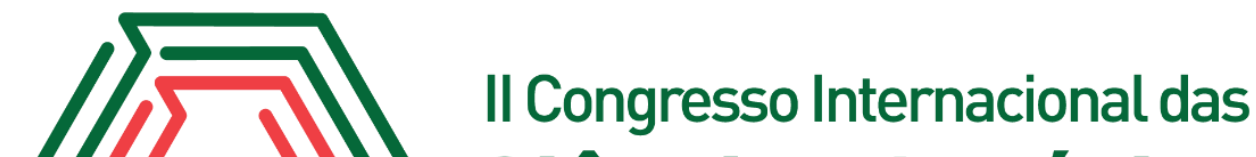 Ciências Agrárias COINTER - PDVAgro 2017
}

\section{EDUCAÇÃO AMBIENTAL: UMA PERCEPÇÃO SOBRE AGROECOLOGIA}

\author{
Apresentação: Pôster
}

Caliane Lília Leite do Nascimento ${ }^{1}$; Lucas Gabriel Veríssimo Pinheiro da Silva ${ }^{2}$; Isadora Natália Rocha Barreto ${ }^{3}$; Rosangela Lopes Dias ${ }^{4}$

\section{Introdução}

A escola é um espaço valoroso para a formação de cidadãos conscientes e capazes de discernir e decidir sobre as questões socioambientais do meio em que está inserido. Nesse contexto, a Educação Ambiental não se restringe somente a preservação da natureza, mas a interação entre o homem e o meio ambiente, bem como as possíveis transformações que possam existir a partir dessa interação. Dessa forma, no contexto agrário brasileiro, a Agroecologia agrega-se como elemento estratégico da educação ambiental possibilitando a um debate amplo que incluem tanto as relações dos agroecossistemas, com técnicas agrícolas, como variáveis econômicas, sociais, políticas, culturais e éticas.

O presente trabalho é parte do projeto "Horta escolar" desenvolvido pelo Centro de Ensino Integrado de Maracajaú (CEIMAR), localizado na zona rural do município de Maxaranguape-Rio Grande do Norte. A pesquisa foi desenvolvida em parceria com a Organização Não Governamental Associação de Proteção e Conservação do Cabo de São Roque e trata-se de uma pesquisa exploratória, delineada num estudo de caso cujo objetivo é identificar qual a percepção de alunos do CEIMAR sobre a agroecologia e se há necessidade de aprofundamento sobre o tema, tendo em vista a restauração da horta existente na escola e continuidade do projeto supracitado.

\section{Fundamentação Teórica}

A questão ambiental emerge de uma problemática social, econômica, ecológica e política,

\footnotetext{
${ }^{1}$ Agronomia, Universidade Federal do Rio Grande do Norte, calileite1@hotmail.com

${ }^{2}$ Ciências Biológicas, Universidade Potiguar, lucasgabrielvps@hotmail.com

${ }^{3}$ Ciências Biológicas, Universidade Potiguar, Isadora.n.rb@gmail.com

${ }^{4}$ Mestre, Universidade Potiguar, rosangelaldias@hotmail.com
} 
propondo uma verdadeira revolução ideológica e cultural que problematiza o conjunto de conhecimentos teóricos e práticos da atualidade (BERNARDES; MATOS; NEHME, 2013). Nesse sentido, a Educação Ambiental surge como proposta para auxiliar no enfrentamento dos desafios socioambientais que assolam o Brasil no século 21. Assegurada pela Lei $\mathrm{n}^{\circ} 9.795$, de 27 de abril de 1999, que dispõe sobre a educação ambiental, institui a Política Nacional de Educação Ambiental e dá outras providências. (BRASIL, 1999) e pelas Diretrizes Curriculares nacionais para a Educação Ambiental, esse modelo de educação, segundo Ritter, Castelan e Grigoletto (2013), se constituí numa forma abrangente de educação, que se propõe atingir todos os cidadãos, através de um processo pedagógico participativo permanente que procura incutir no educando uma consciência crítica sobre a problemática ambiental, compreendendo-se como crítica à capacidade de captar a gênese e a evolução de problemas ambientais.

No contexto agrário brasileiro, a modernização da agricultura engendrou concentração de terra e renda, êxodo rural, dependência tecnológica, insegurança quanto à origem e qualidade do alimento, maior compactação e erosão dos solos, contaminação por uso indiscriminado de agroquímicos e redução da cobertura florestal nativa. Com isso, as discussões sobre as práticas modernas de agricultura, passaram a adentrar no contexto da sustentabilidade. Nessa perspectiva, e em conformidade com a necessidade de trabalhar a educação ambiental, é conveniente a abordagem Agroecológica e todo o conhecimento amplo que sua prática revela.

A agroecologia corresponde a um campo de estudos que pretende o manejo ecológico dos recursos naturais, para- por meio de uma ação social coletiva de caráter participativo, de um enfoque holístico e de uma estratégia sistêmica- reconduzir o curso alterado da co-evolução social e ecológica, mediante um controle das forças produtivas que estanquem seletivamente as formas degradantes e exploradoras da natureza e da sociedade (Sevilla e González, 1996; Caporal, 2009).

Segundo Caporal (2002), os primeiros objetivos da pesquisa agroecológica é a otimização do equilíbrio do agrossistema como um todo, o que significa a necessidade de uma maior ênfase no conhecimento, na análise e na interpretação das complexas relações existentes entre pessoas, os cultivos, o solo, a água e os animais. E, sendo a escola um espaço importante para a formação de cidadãos capazes de discernir e decidir sobre as questões socioambientais do meio em que está inserido, é por ela - através da educação ambiental- que deve iniciar os questionamentos e enfretamentos sobre o atual modelo de organização social, de produção e de consumo brasileiro. 


\section{Metodologia}

Trata-se de uma pesquisa exploratória, delineada num estudo de caso realizado no Centro de Ensino Integrado de Maracajaú (CEIMAR), localizado no distrito de Maracajaú, zona costeira do município de Maxaranguape - Rio Grande do Norte. Foi aplicado um questionário no mês de Outubro de 2017, em alunos do $6^{\circ}$ ao $9^{\circ}$ ano, totalizando 93 alunos. O questionário continha perguntas fechadas, elaboradas de acordo com levantamento bibliográfico e selecionados os modelos de perguntas sugeridas por Ferreira, Ferreira e Mendonça (2009), Ritter, Castelan e Grigoletto (2013) e Fernandes, Silva e Guerra (2013).

Após a aplicação do questionário, foi realizada a interpretação e tabulação dos dados coletados com o auxilio do programa Microsoft Office Excel, no qual foram gerados os gráficos e tabelas.

\section{Resultados e Discussões}

O primeiro ponto a ser discutido é a correlação dos alunos sobre o que eles acreditam ser agroecologia. A maioria, 35,46\%, dos alunos entendem que a agroecologia é ciência que estuda a relação do homem e o meio ambiente de forma sustentável. Com isso, é possível inferir que a maioria das crianças compreende como uma ciência, facilitando apontar a importânci dessa ciência no contexto socioambiental em que a comunidade está inserida. Ainda assim, foi observado que $32,26 \%$ dos alunos relacionaram a agroecologia com a produção de alimentos orgânicos, 22,58\% com técnicas que excluí o uso de agrotóxicos da produção e apenas 9,7\% dos alunos acredita que está relacionado ao manejo sustentável de floresta. Observa-se de forma simplista que ambas as respostas estão precisas, comprovando o que afirma Caporal (2002) quando diz que agroecologia nos lembra uma agricultura menos agressiva ao meio ambiente.

Quando questionado se as crianças acreditam que a agroecologia pode ser utilizada como fonte de renda na agricultura familiar, 89,25\% afirmaram que sim. Desse modo, nota-se que há o desenvolvimento da ideia de relação econômica e desenvolvimento sustentável, podendo explorar dos alunos uma visão agroecológica empreendedora.

Houveram duas perguntas que fundamentaram a pesquisa, a primeira foi se os alunos já ouviram falar sobre a agroecologia e a segunda se eles tinham interesse em participar de curso ou palestra sobre a agroecologia. Em resposta a primeira, 60,21\% dos alunos responderam que sim, já ouviram falar na escola e/ou por meios de comunicação (tv's, internet, rádio entre outros), 
mostrando que a escola está cumprindo seu papel e que há certo conhecimento dos alunos. Já em resposta a segunda pergunta, foi concluído que $22,58 \%$ tinham interesse em participar de palestra, $52,67 \%$ se interessam em participar de curso, 9,7\% já participou de curso ou palestra e 15,05\% não se interessam pelo assunto.

\section{Conclusões}

A pesquisa proporcionou compreender que o alunos do Fundamental II do Centro Integrado de Maracajaú conseguem assimilar o que se trata a agroecologia. Foi observado interesse em compreender mais sobre o tema, no entanto há necessidade de ser abordada de forma prática, na realidade local, favorecendo a continuação do projeto "horta escolar".

\section{Referências}

BERNARDES, Maria Beatriz Junqueira; MATOS, Patrícia Francisca de; NEHME, Valéria Guimarães de Freitas. Educação Ambiental e Agroecologia nas Escolas do Campo. Brazilian Geographical Journal: Geosciences and Humanities research medium. Ituiutaba, p. 436-447. Jul./Dez. $2013 . \quad$ Disponível em: <http://www.seer.ufu.br/index.php/braziliangeojournal/article/view/23566>. Acesso em: 04 set. 2017.

BRASIL. Constituição (1999). Lei no 9795, de 28 de abril de 1999. Dispõe sobre a educação ambiental, institui a Política Nacional de Educação Ambiental e dá outras providências.. Lei no 9.795, de 27 de Abril de 1999.. Diário Oficial , p. 1.

CAPORAL, F.R. et al. Agroecologia: uma nova ciência para apoiar a transição a agriculturas mais sustentáveis. In: Agroecologia: uma ciência do campo da complexidade. Brasilia, p. 9-64, 2009.

CONSELHO NASCIONAL DA EDUCAÇÃO/CONSELHO PLENO (CNE/CP 2/2012).. Resolução $\mathrm{n}^{\circ}$ 2, de 18 de junho de 2012. Estabelece as Diretrizes Curriculares Nacionais para a Educação Ambiental.. Diretrizes Curriculares Nacionais Para A Educação Ambiental. Brasília, DF: Diário Oficial da União, 18 jun. 2012. Seção 1, p. 70-70.

FERREIRA, Ana Paula de Medeiros; FERREIRA, Ana Paula da Silva de Oliveira; MENDONÇA, Marcelo Rodrigues. A AGROECOLOGIA NO CONTEXTO ESCOLAR DO MUNICÍPIO DE CATALÃO (GO): RESULTADOS DE UMA EXPERIÊNCIA. In: XIX ENCONTRO NACIONAL DE GEOGRAFIA AGRÁRIA, 19., 2009, São Paulo. Anais... . São Paulo: Xix Enga, 2009. p. 1 20. Disponível em: <http://www.geografia.fflch.usp.br/inferior/laboratorios/agraria/Anais XIXENGA/artigos/Ferreira_APM.pdf>. Acesso em: 30 set. 2017.

FERNANDES, Roberto da Rosa; SILVA, Andressa Aparecida da; GUERRA, Marcelo. AGROECOLOGIA, DESENVOLVIMENTO SUSTENTÁVEL E EDUCAÇÃO AMBIENTAL. In: 
SEMINÁRIO REGIONAL E FÓRUM DE EDUCAÇÃO NO CAMPO, Não use números Romanos ou letras, use somente números Arábicos., 2013, Santa Maria. Anais... . Santa Maria: Sifedoc, 2013. v. 1. Disponível em: <http://coral.ufsm.br/sifedocregional/images/Anais/Eixo 03/Roberto da Rosa Fernandes.pdf $>$. Acesso em: 15 set. 2017.

FREITAS, Helder Ribeiro; GONÇALVES-GERVÁSIO, Rita de Cássia Rodrigues; MARINHO, Cristiane Moraes; FONSECA, Alex Sandro Silva; QUIRINO, Anny Karoline Rocha; XAVIER, Kerly Mariana Marques dos Santos; NASCIMENTO, Paulo Vitor Pereira do. Horta escolar agroecológica como instrumento de educação ambiental e alimentar na Creche Municipal Dr. Washington Barros - Petrolina/PE. Extramuros, Petrolina-PE, v. 1, n. 1, p. 155-169, jan./jul. 2013.

RITTER, Alexander; CASTELAN, Simone Elenice; GRIGOLETTO, Cassiana. AGROECOLOGIA, DESENVOLVIMENTO SUSTENTÁVEL E EDUCAÇÃO AMBIENTAL. In: SEMINÁRIO REGIONAL E FÓRUM DE EDUCAÇÃO NO CAMPO, Não use números Romanos ou letras, use somente números Arábicos., 2013, Santa Maria. Anais... . Santa Maria: Sifedoc, 2013. v. 1. Disponível em: <http://coral.ufsm.br/sifedocregional/images/Anais/Eixo 03/Alexander Ritter.pdf>. Acesso em: 15 set. 2017.

MINISTÉRIO DA EDUCAÇÃO. Resolução no 2, de 15 de junho de 2012. Estabelece as Diretrizes Curriculares Nacionais para a Educação Ambiental.. Diretrizes Curriculares Nacionais Para A Educação Ambiental. Brasília, DF, Disponível em: $<$ http://portal.mec.gov.br/index.php?option=com_docman\&view=download\&alias=10988-rcp00212-pdf\&category_slug=maio-2012-pdf\&Itemid=30192>. Acesso em: 24 set. 2017. 